\title{
Survey and analysis on soundscape of hydrophilic space in Yitong River, Changchun
}

\author{
Dong Junyan ${ }^{1,2, a}$, Cheng Wen ${ }^{1}$, Ma Chuanpeng ${ }^{2, b}$, Xin Lisen², Tan Yuetong ${ }^{2}$ \\ ${ }^{1}$ School of Architecture, Harbin Institute of Technology, Harbin, China \\ ${ }^{2}$ School of Architecture and Design, Changchun Institute of Technology, Changchun, China \\ ${ }^{3}$ International Asia Art Academy, Banggkok Thonburi University, Bangkok, Thailand \\ adjyrob@gmail.com, b93045611@qq.com
}

\begin{abstract}
Keywords: acoustic landscape, waterfront space, objective measurement, subjective evaluation Abstract. Acoustic environment is one of the important factors affecting the overall urban environmental quality. In this paper, the public space in the hydrophilic spatial zone along the Yitong River in Changchun was chosen as the object of study. Test points were selected for the measurement and statistics of sound pressure level and sound type. At the same time, Subjective questionnaire survey was conducted on some representative points in the different types of hydrophilic spaces around Yitong River. Depth study of the waterfront space soundscape composition and preference evaluation and other influencing factors. The conclusion can provide the basis for the improvement of urban waterfront space environment quality, especially the soundscape design and reconstruction of waterfront space in cold city.
\end{abstract}

\section{Introduction}

The study of soundscape is closely related to many interdisciplinary subjects. It should not only integrate with the planning, landscape and architectural design of modern cities, but also correctly apply all relevant cross-disciplinary research results to the soundscape research platform.

The hydrophilic spatial zone along the Yitong River in Changchun was selected as the site for this study. The open space along the Yitong River can not only affect the layout of ecological planning along the Yitong River, but also has the characteristics of urban culture and cold-region landscape. The construction of open space along the Yitong River is of great practical and historical significance to enhance the cohesion of urban residents, develop urban features, advocate the low-carbon lifestyle and improve the urban ecological quality. In this study, the method of combining physical investigation with social survey was adopted. Typical test points around the Yitong River were selected to make measurement and statistics of the sound pressure level and sound type. Meanwhile, some representative points covering different types of hydrophilic space near the Yitong River were chosen for a questionnaire survey.

\section{Analysis of objective physical measurement}

Research results of regional sound pressure level. According to data measured on the sound pressure level of 9 significantly-different test points around the Yitong River respectively in 4 seasons (spring, summer, autumn and winter), in each season, the sound environment of the Yitong River has an obvious characteristic that except hydrophilic space (Test point 1 and Test point 9) which is relatively far from the traffic line, the other test points have a sound pressure level of higher than $60 \mathrm{~dB}$. In particular, in hydrophilic space which is close to the traffic line, the sound pressure level measured is greater than $70 \mathrm{~dB}$. Figure 1 reflects the change of sound pressure level at different seasons. From Figure 1, it can be seen that the sound pressure level in waterfront space of the Yitong River is at a higher level in summer and autumn, and the sound pressure level of Test point 1, Test point 4, Test point 8 and Test point 9 is the lowest in winter. 

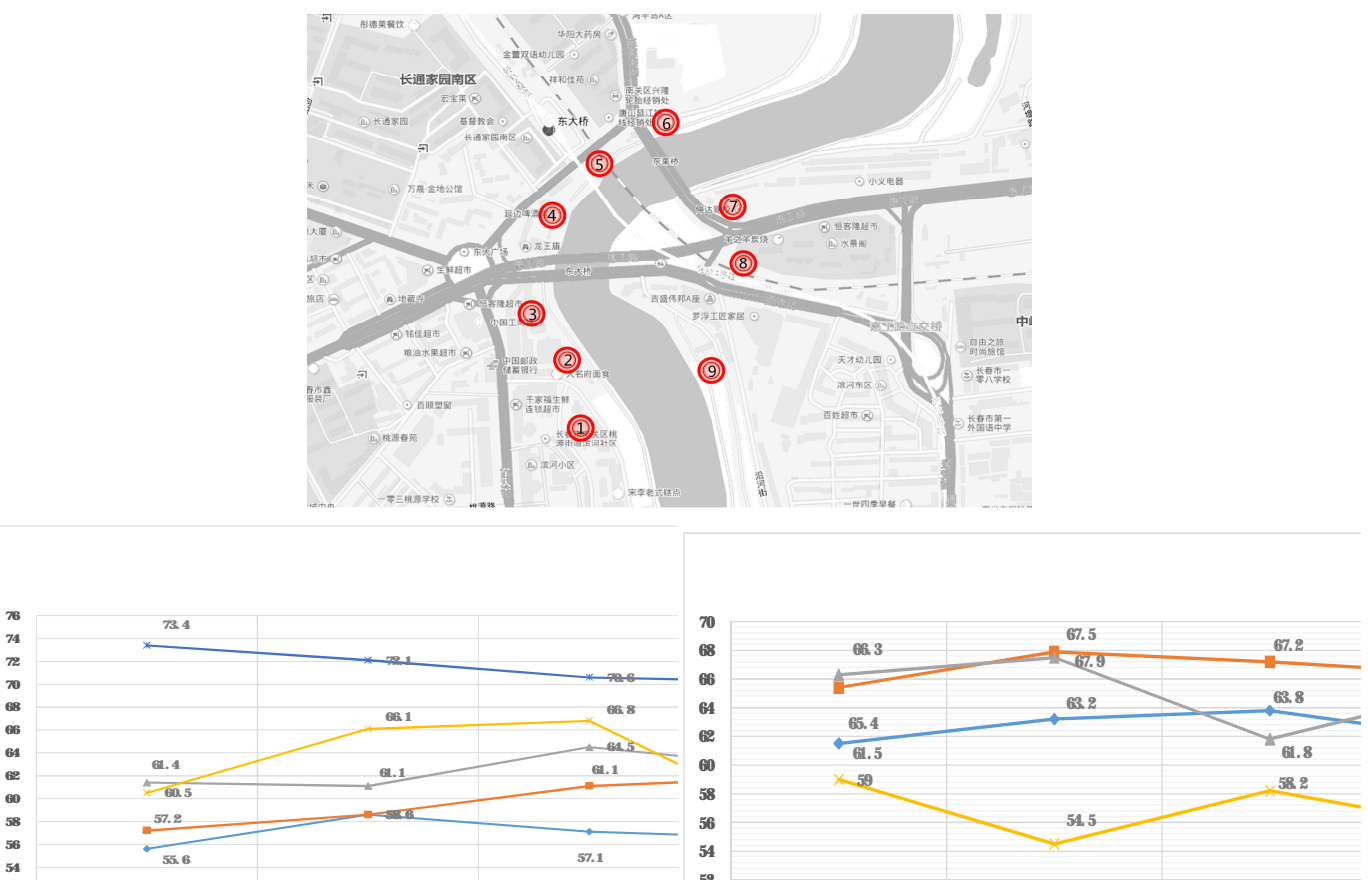
a) Test point $1-5$
b) Test point 6-9

Figure 1 The change of sound pressure level at different seasons

To gain a more precise and timely understanding of the sound environment in the recreation zone of the Yitong River, respondents in test points were interviewed directly to achieve a more thorough and detailed mastery of elements constituting sound in this area. Sound types that the respondents reflect according to the personal experience were sorted out and analyzed. Sound elements in the recreation zone of the Yitong River can be roughly divided into 3 categories. The first category of sound refers to the artificially mechanical sound source, including music played, car whistle and construction; the second category of sound refers to the artificially natural sound, such as the child sound of playing, laughing, fighting and quarreling, pedestrian noise and yo-heave-ho; the third category refers to the natural sound, including bird calls, leaves' rustle, wind sound, and pet calls. Sound elements have 12 sound sources.

Analysis of physical measured results. In summary, in the waterfront recreation zone near the Yitong River, except for test points which are far away from the main traffic line, the sound pressure level of other test points is basically higher than $60 \mathrm{~dB}$. In particular, for some test points which are close to traffic arteries, their sound pressure level is greater than 70dB.According to researchers' evaluation of sound articulation and comfort, if the measured value of sound articulation in a test point is not high, researchers would certainly evaluate the sound environment of this test point as "uncomfortable". On the contrary, if the measured value of sound articulation in a test point is high, research would mostly evaluate the sound environment of this test point as "comfortable". However, even if measured value of sound articulation in a test point is high, researchers may evaluate the sound environment of this test point as "uncomfortable". Therefore, future efforts will be put to discuss whether sound articulation is an important index to reflect the sound environment quality of a test point.

\section{Analysis of subjective survey of respondents}

Respondents' evaluation of the sound environment in the study area. After field research and survey at this stage, comprehensive calculation and classifications were made of sound that people around the hydrophilic space of the Yitong River can hear.According to statistical data on the sound 
environment in 4 seasons, the sound environment of the Yitong River shares commonalities in spring, summer, autumn and winter. Respondents are relatively easy to hear the construction sound, car whistle, wind sound, and the noise of pedestrians, while just a small number of respondents can notice the sound from nature, such as rustling of falling leaves and birdcalls. This result is consistent with the above-mentioned test result of the sound environment in the study area. The proportion of attention to water sound, pedestrian noise and child sound of playing, laughing, fighting and quarreling in spring, summer and autumn is slightly higher than that in winter. According to statistical data on attention to sound in each season, the gap in the attention to different sound in winter is the smallest, while the gap in the attention to different sound in spring, summer and autumn is not large. This indicates that in spring, summer and autumn, the distinction between the sound elements is more obvious, which is more beneficial to the design of sound environment, while in winter, the distance between the sound elements is not obvious due to the influence of weather.

Using SPSS to analyze the impact of subjective evaluation data. During the course of the survey, respondents were asked to give a subjective comment on the comfort of the environment and the sound environment to see if environment comfort and sound environment comfort were intrinsically linked. SPSS, as statistical software, was used, and the bi-variate correlation method was adopted to check whether sound comfort and sound environment comfort have correlations. According to data surveyed (Table 1), the Pearson's correlation coefficient between environment comfort and sound environment comfort is 0.478 , indicating that environment comfort and sound environment comfort have a significant correlation [6]. This implies that a good sound environment is quite beneficial to the improvement of the overall environment comfort, so the quality of sound environment can affect the quality of overall environment.

\section{Table 1 Correlation between environment comfort and sound environment comfort}

\begin{tabular}{lll}
\hline & Environment comfort & Sound environment comfort \\
\hline Pearson's /correlation & 1 & $0.478^{* *}$ \\
Significance & & 0.000 \\
Square and cross products & 361.977 & 179.288 \\
Covariance & 0.727 & 0.316 \\
N-value & 479 & 479 \\
Pearson's /correlation & $0.478^{* *}$ & 1 \\
Significance & 0.000 & \\
Square and cross products & 179.288 & 376.055 \\
Covariance & 0.295 & 0.791 \\
N-value & 479 & 479 \\
\hline
\end{tabular}

**indicates statistical significance (two-sided) at the $1 \%$ level.

Through SPSS, this study investigated different sound types in 4 seasons from different perspectives, and adopted the method of comparing 2 variables to analyze data obtained. The method of variance analysis (See Table 2) was used to describe 12 sound sources. Results of the variance analysis showed that the 12 sound sources bear great differences, but no great difference exists between different classes. Based on above results, it can be concluded that the evaluation on the car whistle and noise of construction sites is the worst, so the generation of these 2 sound types should be reduced as much as possible in the planning of the soundscape for the Yitong River. However, the sound from nature, such as birdcalls and leaves' rustling, have quite good evaluations, so the generation of these sound types should be increased in the soundscape planning.

Table 2 Results of variance analysis

\begin{tabular}{lccccc}
\hline & Sum of squares & df & Mean square & F & Significance \\
& & & & & 0.000 \\
Inter-class variance & 140.246 & 13 & 11.976 & 92.749 & \\
Intra-class variance & 806.799 & 5759 & 0.140 & & \\
Total & 947.045 & 5772 & & & \\
\hline
\end{tabular}


On the whole, combined with the above results, this study can conclude that in the soundscape planning for this area, recreation zones like squares in European countries should be properly built to provide a public space for relaxation and recreation to respondents. In addition, special methods of acoustics can be used to minimize the inference of the car whistle and noise from construction. Landscape and green building should be arranged to add some natural sound to the Yitong River. The distribution trend of evaluation on sound that people like and want to hear is generally the same. This indicates that the value of evaluation on the traffic whistling and construction noise is quite small, and bears a significant difference from the value of evaluation on other sound types. Therefore, in the soundscape planning, the generation of traffic whistling and construction noise should be reduced as much as possible. The value of evaluation on the child noise of playing, laughing, fighting and quarrelling, music sound, birdcalls and wind sound is relatively high, so these sound types should be increased in the soundscape planning.

As can be seen from the above figure, the sound and environment has a quite close relationship. A high-quality sound environment can have a great impact on the environment quality in this area. Therefore, this finding can be used as theoretical basis for future soundscape development and planning. Moreover, various types of sound simultaneously exist in hydrophilic space of the Yitong River. However, many people usually amplify sound annoying them, but rarely amplify sound that they like or want to hear. Lastly, on the one hand, the traffic whistling and construction noise are quite obvious in this area and also the least popular sound. On the other hand, the child sound of playing, laughing, fighting and quarrelling, the music, birdcalls and wind sound are sound types that people most like to hear. However, these sound types are rarely heard in this area. Therefore, attention should be paid to the 2 aspects in the future soundscape development and planning.

\section{Conclusions}

Yitong River is a major project in urban construction of Changchun. It has great significance in the process of building and improving the city. Hydrophilic space on both sides of the Yitong River will become an indispensable place for recreation, entertainment and outdoor sightseeing of urban residents in the future. Therefore, it is not enough to evaluate the environment quality of this area and judge whether sound environment is affected by the environment quality simply at the visual level. In response to this problem, physical measurement and questionnaire surveys were used to conduct detailed and normative research on the sound environment in hydrophilic space of the Yitong River. Government departments should increase capital investment on the improvement of the sound environment quality on both sides of the Yitong River. SPSS is used to make induction and analysis, and find an obvious correlation between sound and environment. This also indicates that even if the environment quality is partly improved, defects in the sound environment have some shock to the high quality of hydrophilic space.

\section{Acknowledgements}

This work was financially supported by Science and Technology Project Foundation of Ministry of Housing and Urban-Rural Construction of the People's Republic of China (No. 2016-R-2005), Jilin Provincial Social Science Foundation (No.2015-BS-83), Youth Foundation of Changchun Institute of Technology (No.320140006) and Teaching reform project of Changchun Institute of Technology.

\section{References}

[1] Junyan Dong, Hong Jin. The design strategy of green rural housing of Tibetan areas in Yunnan, China. Renewable Energy, Vol. 49, pp. 63-67. 
[2] Junyan Dong, Wen Cheng. Based on the Characteristics of Respondents and the Voice of the Urban Neighborhood Public Space Business Facilities Noise Environment Evaluation Research. Journal of Harbin Institute of Technology.2014 ,20(4),pp.103-109.

[3] Junyan Dong, Hong Jin, Jian Kang, Xi Chen, A pilot study of the acoustic environment in residential areas in Harbin, towards the questionnaire design. Journal of Harbin Institute of Technology.2011,18(2),pp.319-322. 